\title{
Voltammetric analysis of Dopamine in the Presence of Large Concentration of Ascorbic Acid at Nickel Oxide-Gold Nanoparticles Binary Electrocatalyst
}

\author{
Zahrah T. Al-thagafi ${ }^{1,2}$, M. I. Awad ${ }^{1,3, *}$ \\ ${ }^{1}$ Chem. Department, Faculty of Applied Sciences, Umm Al-Qura University, Makkah, Saudi Arabia. \\ ${ }^{2}$ Chem. Department, Faculty of Sciences, Taif University, Taif, Saudi Arabia. \\ ${ }^{3}$ Chem. Department, Faculty of Science, Cairo University, Cairo, Egypt. \\ *E-mail: mawad70@yahoo.com
}

doi: $10.20964 / 2020.06 .56$

Received: 1 February 2020 / Accepted: 24 March 2020 / Published: 10 May 2020

\begin{abstract}
The current investigation presents electrodeposition of nickel oxide (nano- $\mathrm{NiO}_{\mathrm{x}}$ ) and gold nanoparticles (AuNPs) onto glassy carbon electrode $\left(\mathrm{GC} / \mathrm{NiO}_{\mathrm{x}}-\mathrm{Au}\right)$, and the subsequent application of this electrode for the analysis of dopamine (DA) in the presence of excess concentration of ascorbic acid (AA). Based on its catalytic function towards the oxidation of DA and AA, the overlapping voltammetric response of the DA and AA at the bare electrode is resolved into two well-defined voltammetric peaks with lowered oxidation potential and enhanced oxidation currents. The sequence of deposition sequence of nano- $\mathrm{NiO}_{x}$ and AuNPs was adjusted for tuning the electrocatalytic activity and sensitivity. The highest catalytic activity and sensitivity towards the two species was obtained at the electrode modified by $\mathrm{NiO}_{\mathrm{x}}$ and then AuNPs. Also, the modified electrode has been electrochemically and morphologically characterized using SEM, EDX and XRD. The practical analytical utility of the electrode is illustrated by the simultaneous determination of DA and AA in real samples (commercially available pharmaceutical formulation) without any preliminary treatment.
\end{abstract}

Keywords: Electrocatalysis, Gold nanoparticles, Nickel oxide nanoparticles, Glassy carbon electrode, Dopamine, Ascorbic acid

\section{FULL TEXT}

(C) 2020 The Authors. Published by ESG (www.electrochemsci.org). This article is an open access article distributed under the terms and conditions of the Creative Commons Attribution license (http://creativecommons.org/licenses/by/4.0/). 